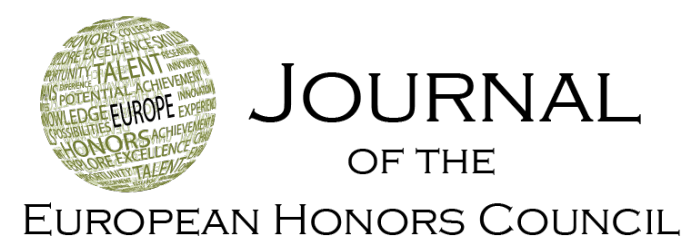

Note

\title{
Honors in the Time of Corona
}

John Zubizarreta

Columbia College, USA

Correspondence: jzubizarreta@columbiasc.edu

Received: 1 June 2020; Accepted: 3 June 2020; Published: 4 June 2020

\begin{abstract}
All of us who love what we do as teachers; who love our disciplines, scholarship, and students; who thrive on the challenges and rewards of honors education-we all have faced many new obstacles and disappointments caused by the COVID-19 pandemic. Having resources to help us deal with the shifts is key to moving forward. While many concerns have surfaced in our profession, this essay's collection of international resources focuses on four topics that affect honors in immediate ways: retooling faculty approaches to teaching; addressing student access and success; adapting capstone projects and presentations to online delivery and assessment; and adjusting grades (always a big factor in honors recruitment, retention, scholarships, alumni pathways, and more). To make the collection more useful, the list of resources includes some brief annotations to help organize and preview the items.
\end{abstract}

Keywords: COVID-19; online teaching; remote learning; pedagogy resources

\section{Introduction}

Any of you familiar with the novels of Colombian novelist Gabriel Garcia Márquez will probably recognize the inspiration behind my title, even if the correspondence is a bit of a stretch. His novel Love in the Time of Cholera rings of passion, disappointment, delayed fulfillment, and the fear and disruptions caused by pandemic disease. All of us who love what we do as teachers-who love our disciplines, scholarship, and students; who thrive on the challenges and rewards of honors education-have faced many new obstacles and disappointments caused by the COVID-19 pandemic. The prevalent fear and disruptions that have become the 'new normal' in our lives have resulted in having to delay the fulfillment that usually comes with the satisfaction of a dynamic classroom discussion, an energizing conference with a student in our office over an exciting project idea, a round of applause at a senior capstone presentation, or a wave of proud smiles at a commencement celebration. 
Honors-indeed all of higher education -in the time of the Coronavirus infection has inexorably changed; having resources to help us deal with the shifts in philosophy, priorities, and practices in our pedagogy is key to moving forward.

At the time of my composition of this compilation of helpful information, practical tips, and model responses to the pandemic crisis, we are told by world health professionals, international government leaders, and popular media that the end of the situation is not immediately in sight. Many institutional administrators predict that taking our teaching and learning and other professional and scholarly duties online in order to comply with worldwide 'social distancing' and 'stay-at-home' orders will likely extend indefinitely beyond the present to future semesters. Undoubtedly, the sudden demand to 'go remote' has upended much of what we have always done well in honors and why and how we have done it. The need to adapt has been difficult, but it has also opened up new opportunities, new avenues for rethinking and redesigning our pedagogical approaches. For instance, perhaps now honors is ready to reconsider the notion that honors and 'distance learning' are antithetical propositions. Having been compelled to adapt to remote teaching, learning, and program management in order to continue to challenge, encourage, support, and reward our students (and faculty), perhaps now we can reimagine how the honors experience can be sustained and even enhanced by technology. Brave new world. Honors in the time of Corona ... and after.

As co-chair of the National Collegiate Honors Council (NCHC) Teaching and Learning Committee (T\&L) and a subscribing member of the European Honors Council (EHC), I have taken a strong, vested interest in sharing resources with honors colleagues through email, publications, and other means of communication. My enthusiasm for conversations about teaching and learning has grown from my career-long association with the Professional and Organizational Development Network in Higher Education (POD) and the international world of faculty development and teaching and learning centers. Many of the resources I cite in this essay are borrowed from the generous contributions of dedicated faculty development colleagues affiliated with such global networks. Given the rapid changes that often occur in web addresses, some of the links in the following list of resources may not work properly, but with a little creativity and tenacity, readers can still find the information.

Worldwide conversations have emerged about online issues such as how to administer and evaluate traditional tests and quizzes; how to proctor student work; how to deal with breaches of academic integrity; how to use or not use routine student evaluations of courses that have gone remote at midstream; how to continue or delay typical faculty promotion and tenure requirements and timelines-and these are just a few of the many serious concerns that have forced reconsideration of business-as-usual. However, I restrict my focus here to four topics that affect honors in immediate ways: retooling faculty approaches to teaching; addressing student access and success; adapting capstone projects and presentations to online delivery and assessment; and adjusting grades (always a big factor in honors recruitment, retention, scholarships, alumni pathways, and more) to accommodate the unexpected, sudden shifts in course design, pedagogy, and assessment. To make the collection more useful, I have added some brief annotations to help organize and preview the items. 


\section{Resources for Remote Teaching and Learning}

- The International Association of Universities (IAU) provides a list of abundant resources that also link to worldwide higher-education responses to the challenges of teaching and learning during COVID-19: https://www.iau-aiu.net/Covid-19-HigherEducation-challenges-and-responses

- Utrecht University has assembled a valuable array of tips and tools on remote teaching, ranging from an assessment framework to handling lectures, digital laboratories, testing, proctoring, and more: https://www.uu.nl/en/education/quality-and-innovation/remote-teaching

- Daniel Stanford of DePaul University has compiled an evolving comprehensive list of almost 450 institutional responses from different countries to the urgent call for continuity of teaching and other business: http://bit.ly/rtresourcelist

- The University of lowa's faculty development resources include a site full of valuable, practical tips for faculty moving their courses to the online environment: https://teach.uiowa.edu/keep-teaching-iowa

- lowa's resources also include useful video lessons in their Extraordinary Teaching Project:

- $\quad$ How to give brief, effective feedback to written or performative work through short video clips: https://teach.its.uiowa.edu/grading-recordedclips

- How to facilitate group work in distance classes: https://teach.its.uiowa.edu/extraordinary-teaching-project-engagingstudents-online

- An excellent collection of practical, quick-to-implement approaches to a number of issues that faculty encounter when moving instruction online has been created by U.S. Professor of the Year Steven Volk of the Great Lakes Colleges Association/Global Liberal Arts Alliance: http://glcateachlearn.org/going-online-fast-resources-to-helpyou-move-your-instruction-online/

- UNESCO's Global Education Coalition provides many resources for responding to the pandemic's effect on educational institutions and on teaching and learning from primary schools to colleges and universities: https://www.insidehighered.com/digital-learning/article/2020/05/13/one-optiondelivering-instruction-if-campuses-open-fall-hyflex

- Daniel Stanford of DePaul University has created an IDDblog post, 'Videoconferencing Alternatives: How Low-Bandwidth Teaching Will Save Us All.' Both faculty and students will likely continue to face challenges of redesigning courses and ensuring equitable access. The bottom-line lesson in this piece and in others is keep it simple! Low-tech, familiar, simple strategies often work best, especially when both faculty and students are struggling with disrupted patterns of teaching and learning: https://www.iddblog.org/videoconferencing-alternativeshow-low-bandwidth-teaching-will-save-us-all/

- Erasmus University Rotterdam offers many useful resources on topics such as creating videos, assessment and grading, communication with students, and more: https://www.eur.nl/en/about-eur/vision/community-learning-andinnovation/advice-online-education 
- Here is a useful link from Roanoke College, a strong liberal-arts college, dealing, like all of us, with challenges of going online. The site offers an honest, sensible set of guidelines and tips: https://www.roanoke.edu/teaching/continuity

- The European University Association has links to several resources: https://eua.eu/news/494:resources-for-digital-learning-and-teaching-during-thecoronavirus-pandemic.html

- Annette Schwabe of Florida State University's honors program shares in an email a colleague's website on teaching remotely, with the mantra 'People first. Content second. Technology third': https://vanessadennen.com/teaching-online-duringcovid-19/

- NCHC Executive Director, Mary Beth Rathe, contributed these sites to the NCHC Forum (13 Mar. 2020):

- $\quad$ The Instructional Design-Emergency Response Network: https://sites.google.com/view/idernetwork/home

- $\quad$ 'Moving Online Now' - a free resource from The Chronicle of Higher Education: https://connect.chronicle.com/CS-WC-2020CoronavirusFreeReport LP-SocialTraffic.html

- The NCHC Online Toolkit: https://nchc.site-ym.com/page/onlinehonorscourses. This toolkit provides links to an online video presented by Victoria Bryan of Cleveland State Community College. The video is also available at https://www.youtube.com/watch?v=GxnL-XasW6A

- One particularly challenging dimension of online instruction is the issue of how to handle clinicals and labs:

- Here is a gold mine of numerous resources in the various STEM fields for migrating labs to online simulations and virtual labs: https://docs.google.com/spreadsheets/d/18iVSleOqKji58xcR8dYJS5rYvzZ4 X1UGLWhI3brRzCM/edit?usp=sharing

- $\quad$ Geoscience resources for teaching online are available at https://docs.google.com/spreadsheets/d/1R6THvClcAjGrWRspCN915SIzltdZ95ziwiF8BmQrYc/edit\#gid=0

- $\quad$ Ecology and environmental sciences resources for teaching online are described at https://docs.google.com/spreadsheets/d/16K6bGTfwGjxxi6aGi v6vlLQSpsOg|1zq3tXLHWweg/edit\#gid=0

- Harvard's LabXchange shares lab simulations with assessments in biotechnology: https://www.labxchange.org/library/clusters/abe

- $\quad$ MERLOT offers a collection of virtual labs in a variety of science disciplines: https://www.merlot.org/merlot/materials.htm?keywords=virtual+labs\&so rt.property=relevance

- $\quad$ PHET offers interactive simulations in science and math: https://phet.colorado.edu/

- Many textbooks provide interactive lab-based resources

- Dublin Technological University offers useful tips on online teaching and learning, alternative methods of assessment, and FAQs: https://www.dit.ie/aadlt/lttc/keepteaching/

- The Association of College and University Educators (ACUE) has a toolkit for teaching online: https://acue.org/online-teaching-toolkit/. Featuring valuable insights from, among others, U.S. Professor of the Year Mike Wesch, known for his innovative use 
of technology in teaching and learning, the toolkit is organized into the following topics:

1. Welcome students to the online environment

2. Manage your online presence

3. Organize your online course

4. Plan and facilitating quality discussions

5. Record effective micro-lectures

6. Engage students in readings and micro-lectures

- ACUE also has information and tips on responding to COVID-19, with additional links to other valuable sites: https://acue.org/coronavirus/

- Maastricht University's online education site includes abundant strategies and answers to many questions and about remote teaching and learning: https://www.maastrichtuniversity.nl/education/online-education-um/teaching-staff

- The Online Learning Consortium offers resources on 'Continuity Planning and Emergency Preparedness' helpful for instructors needing suddenly to go online: https://onlinelearningconsortium.org/about/continuity-planning-emergencypreparedness-resources/

- Vilnius University's Centre for Teaching Competencies Development offers a variety of resources on moving to online teaching and learning: https://www.vu.lt/en/covid19/teaching-online

- LX Pathways by iDesign is allowing temporary free access to its tools for online course design and pedagogical strategies rooted in 'empathy, compassion, and the human experience': https://Ixpathways.com/

- The Scholarly Teacher blog site has several posts on teaching challenges and solutions prompted by the COVID-19 pandemic: https://www.scholarlyteacher.com/blog/

- Magna Publications offers a coupon for free access to its 'Taking Your Teaching Online Program Collection': https://www.magnapubs.com/product/onlinecourses/taking-your-teaching-online-program-collection/

- The Autonomous University of Barcelona features an array of resources, links, and tips: https://www.uab.cat/web/about-the-uab/itineraries/coronavirus/coronavirus1345809701134.html

- One of my favorite, no-nonsense pieces is available at https://anygoodthing.com/2020/03/12/please-do-a-bad-job-of-putting-yourcourses-online/

- Some gentle advice, humor, and musical relief can be found at:

- $\quad$ http://neatoday.org/2020/03/25/teaching-online-during-coronavirus/

- $\quad$ https://www.facultyfocus.com/articles/philosophy-of-teaching/leadingour-classes-through-times-of-crisis-with-engagement-and-peace/

- $\quad$ https://www.chronicle.com/article/How-to-Recover-the-Joy-of/248314

- $\quad$ https://www.youtube.com/watch?v=8U6zU4MXmnA\&feature=youtu.be\& app $=$ desktop

- $\quad$ https://www.youtube.com/watch?v=CCe5PaeAeew (in which Michael Bruening of Missouri University of Science and Technology strums his anthem to surviving remote teaching) 


\section{Student Access and Support Issues}

Initially, the disruptions caused by the COVID-19 pandemic sent faculty into dizzying tailspins in trying to respond to the mandates to go online. Many faculty members, unfamiliar with and inexperienced in online teaching, have suddenly needed concentrated primers on using an array of technologies and redesigning courses for a different medium. Significant attention in the explosive new literature about online education in a time of crisis has been given to the challenges facing faculty, but as we move increasingly to remote methods of teaching and learning, ensuring that our students have adequate access and skills is also of paramount importance. We presume that all our students are tech savvy and have equal and immediate access to the technology and support they need to succeed in the 'new normal' world of remote education. If we took the time to poll our students about access to necessary devices, sufficient bandwidth, study areas, and other required resources, we would surely discover that access is a major concern. The topic is worth serious attention.

- Delft University provides many sensible and innovative tips and activities aimed at keeping students healthy, safe, and successful during COVID disruptions: https://www.tudelft.nl/en/student/well-being-and-study/

- Many of our students have no experience with or desire to adjust to online learning. They need help. The University of lowa's Office of Teaching, Learning \&Technology provides an excellent, comprehensive guide to help students adapt to the various challenges of remote learning: https://teach.uiowa.edu/keep-learning-iowa

- Rice University's Center for Teaching Excellence offers a detailed, useful set of tips for ensuring student success and addressing concerns about students who may not thrive under the mandates to take courses online. Colleagues worldwide are having the same conversation, trying to pay attention to issues of equity, inclusion, learning preferences, access, and other problems. Rice's site is a step forward: https://cte.rice.edu/blogarchive/2020/3/13/inclusion-equity-and-access-whileteaching-remotely

- The University of Melbourne offers various tips and resources to support students: https://students.unimelb.edu.au/student-support/coronavirus

- The University of Michigan's support site for students offers clear strategies to help students adjust their study habits for successful online learning: https://Isa.umich.edu/content/dam/rll-assets/rll-docs/Study\%2OHabits.pdf

- In addition to a number of helpful tips for students, the University of North CarolinaAsheville has developed a list similar to Michigan's in printable PDF format. Check the link to 'Student Guide: Adjusting to Online Learning' at https://coronavirus.unca.edu/resources/remote-learning-working/

- Among a number of other suggestions for student success during isolation, Amsterdam University of Applied Sciences offers valuable insights on student wellbeing: https://www.amsterdamuas.com/remotelearning/well-being/your-wellbeing.html

- The Student Academic Center at Indiana University-Bloomington has assembled student-friendly advice that includes many links to additional resources: https://sac.indiana.edu/suddenly online/index.html 
- The Experimental Psychology department at Oxford University shares a number of links related to mental health which can help with student support: https://www.psy.ox.ac.uk/covid-19-info/covid-19-resources

- A number of service providers have responded to the massive, emergency shift to online educational methods by offering different levels of free internet access. At the time of this writing in spring 2020, the following announcements demonstrate the actions taken by businesses and non-profits to offer help:

- $\quad$ Some international communications agencies have issued temporary regulations to ease the burden on users during COVID. In the United States, for example, an FCC agreement states that providers will waive late fees, not cut off service for lack of payment, and open hot-spots: https://docs.fcc.gov/public/attachments/DOC-363033A1.pdf

- $\quad$ Comcast COVID-19 response offers free Wi-Fi for two months to lowincome families, and all Xfinity hot-spots are free to the public during this time: https://corporate.comcast.com/covid-19

- Charter/Spectrum offers free internet for two months: https://corporate.charter.com/newsroom/charter-to-offer-free-access-tospectrum-broadband-and-wifi-for-60-days-for-new-K12-and-collegestudent-households-and-more

- $\quad$ AT\&T COVID-19 response offers open hotspots, unlimited data to existing customers, and discounted plans to low-income families: https://about.att.com/pages/COVID-19.html

- Verizon COVID-19 response is in line with the FCC agreement and offers enhanced high-speed data and no data caps: https://www.verizon.com/featured/covid-19-waived-fees-and-charges/

- T-Mobile/Sprint COVID-19 response is consistent with the FCC agreement and includes a few additional offers of unlimited data and some limited free access: https://www.t-mobile.com/news/t-mobile-update-on-covid19-response

- Immigrants in a number of countries face additional issues when they are marginalized from mainstream society, with less or no access to vital resources. In the United States, for instance, where so-called 'Dreamers' (DACA) confront daily issues of prejudice and disenfranchisement, the California Immigrant Youth Justice Alliance has a valuable site to help DACA students in the midst of the pandemic. It might be useful for DACA students in American honors programs and colleges but also for immigrant students in other countries: https://ciyja.org/covid19/

- Students need special support during a crisis. Here is a list of strategies to help students succeed in times of uncertainty: https://www.insidehighered.com/advice/2020/03/17/10-strategies-supportstudents-and-help-them-learn-during-coronavirus-crisis

- Another list of quick tips on reducing student anxiety, with an embedded white paper on the subject, can be found at https://www.insidehighered.com/blogs/universityvenus/student-agency-uncertain-times

\section{Strategies for Honors Capstone Theses and Projects in Remote Environment} There has been quite a conversation circulating internationally about how to deal with senior projects, thesis presentations, doctoral defenses, and such. Except for where 
particular in-house technologies are mentioned as alternatives to face-to-face gatherings, most of the solutions point to using systems such as Zoom, Skype, GotoMeeting, Microsoft Teams, or similar platforms. Most honors programs and colleges include a requirement for completion of a capstone thesis or project, making the problems of delivery and assessment acutely relevant. The challenges are widespread:

- $\quad$ https://cornellsun.com/2020/03/25/covid-19-complicates-some-researchplans-opens-other-new-doors/

- https://dailyutahchronicle.com/2020/03/23/covid-19-student-research/

- $\quad$ https://www.dukechronicle.com/article/2020/03/duke-university-closingdown-covid19-senior-thesis-work

- The Arizona State University honors college site has some information on senior thesis completion and defense: https://barretthonors.asu.edu/about/covidinfosite

- The University of Washington has a detailed, comprehensive page on the effects of the pandemic on research work by faculty, graduate students, and undergraduates: https://www.washington.edu/research/announcements/mitigating-impacts-toresearch-activities-due-to-covid-19/

- The University of Florida has a FAQ page that offers Zoom as an alternative to a faceto-face meeting for thesis defense: http://www.ufl.edu/health-updates/frequentlyasked-questions/\#students

- While the focus is on doctoral dissertations disrupted by the pandemic, the resources shared by Leiden University on new protocols for completing theses and projects can be adapted and applied to undergraduate honors work: https://www.staff.universiteitleiden.nl/vr/remote-research?cf=serviceunits\&cd=administration-and-central-services

- Despite and during disruptions, we can still celebrate our students' projects by recognizing them even if only by mention on our web sites. Here is an example, responding to the pandemic disruption: https://honors.tcu.edu/honors-week/seniorpresentations/

- Honors director Annette Schwabe of Florida State University posted this strategy in the NCHC Forum: 'We will 1. allow/request remote thesis defenses (following from grad school policy); 2 . allow any seniors planning to graduate this spring or summer to complete and defend their theses after graduation, up through the end of fall 2020. We created a virtual form that committee members can sign to confirm that they agree to the extension and sent out messages to students in this group, their thesis directors, and departmental honors liaisons. We will send a list of students who complete their theses after graduation to the Registrar's office, who will add transcript notification to this effect. We have 146 students in this category and even if only a few opt for this, it will be worth it in my mind. It also sends the general message that we want to support our students and hold them harmless from circumstances well beyond their control (and acknowledge that they might or might not have the resources to navigate these uncharted waters as quickly as others)' ( 7 Mar. 2020).

- In an email, honors director Tom Spencer of Texas A\&M University Kingsville to T\&L Committee wrote: 'We're having students present their research in small groups via Blackboard Collaborate' (31 Mar. 2020). 
- In an email to the T\&L Committee, honors director Susan Dinan wrote: 'At Adelphi University we have about 60 students working on honors theses. Each student gave a progress report presentation in February in which they met with their advisors, readers, and the honors staff to present their thesis work up to that point. Most of the students have completed their research and are writing their theses now. They are being urged to speak with their advisors regularly. The honors staff is reaching out to encourage the students and remind them to stay engaged with their advisors. Their defenses will take place over Zoom in later April and early May. In the past, the students submitted a bound thesis to the honors college office, but this year we will request .pdf files sent electronically. We will create an online archive of theses instead of a physical collection. Perhaps this will prove to be a better way to store theses going forward and perhaps it will be easier for students to access them' (31 Mar. 2020).

- In an NCHC Forum post, honors director Matthew Wranovix of the University of New Haven wrote: 'We've decided to have students record presentations in Zoom (using PowerPoint/Prezi/Poster PDF) with screen share, archiving them in a shared Office 365 folder and then posting them to a page in Microsoft Teams. That will allow honors students and faculty to view the presentations and leave questions/comments for the presenters. We're asking the presenters to monitor the comments on their presentations and respond. ... Eventually l'd like to build a webpage to host the presentations, but that will take time. Allowing comments is also 'safer' in a Teams environment rather than out in the wild' (23 Mar. 2020).

- In a post to the NCHC Forum, honors director Marjorie Jolles of Roosevelt University wrote: 'We have asked thesis mentors to be in more frequent touch with students via Zoom, to implement more frequent deadlines for drafts, and whatever else will give students more support and greater sense of mentor presence. For the thesis defense, we've created an asynchronous substitute for the oral presentation, asking thesis writers to create a slideshow that highlights their research question, methodology, argument, and conclusions. Mentors will then send students a couple questions to respond to' (23 Mar. 2020).

- While this NCHC Forum post by honors director Peter Bradley of Ferris State University concerns how the Mid-East Honors Association adapted to an online format, it mentions the use of WordPress as a platform for displaying student projects: 'At MEHA, we moved the entire conference online - you can take a look at https://mideasthonors.org/conference2020/. We retooled our existing submission system, which was based on the blogging platform WordPress, to support a virtual asynchronous conference. Students have created short videos for both posters and presentations, and we're using the blog's standard 'comments' functionality for discussion. You will need to register for the site and be logged in before you can see the videos and participate in discussions' (2 Apr. 2020).

\section{Rethinking Grading Strategies}

Many educators across the globe have discussed shifts to pass/fail grading or some other response to the seismic disruptions to familiar teaching and learning strategies. The issue is critical in honors because grades are often, if not always, at the center of honors recruitment, retention, scholarship selection, awards, grants, and preparation for students' 
success after graduation. In this collection of some of the buzz, you will notice arguments on both sides and some ideas about compromise solutions.

- A blog post with a substantial list of different school policies: https://oudigitools.blogspot.com/2020/03/feedback-alternate-grading-incrisis.html?m=1

- Another expansive list: https://docs.google.com/spreadsheets/d/1yiguffoKBXHDt42eP3pWJkwKGxINC1nOkZ MBRudENf8/edit\#gid=0

- An Inside Higher Ed piece with internal links: https://www.insidehighered.com/news/2020/03/19/colleges-go-passfail-addresscoronavirus

- A Chronicle piece: https://www.chronicle.com/article/Make-All-Courses-Pass-FailNow/248281

- A Citadel university colleague on the web site of the Association for Supervision and Curriculum Development (ASCD): http://www.ascd.org/ascdexpress/vol14/num31/grading-for-mastery-not-mystery.aspx

- An example of a comprehensive, up-to-date school site with vital information, including a response to a question about grades: http://www.ufl.edu/healthupdates/frequently-asked-questions/\#students

- Another example of FAQs related to a revised S/U grading policy from the Teaching and Learning Center at McGill University in Quebec:

- $\quad$ https://www.mcgill.ca/coronavirus/faqs\#Satisfactory/Unsatisfactory\%20o ption

- $\quad$ https://mcgill.ca/tls/instructors/class-disruption/teaching-continuityguide

- A video from Florida International University, in which Senior Vice President Elizabeth Bejar discusses the complexities of changing grading policies (starts around 7:50 in video):

https://www.facebook.com/floridainternational/videos/146324973364458/?vh=e\&d $\underline{\underline{\text { n }}}$

- A sample letter to students about revised grading policies at the University of Puget Sound: https://www.pugetsound.edu/files/resources/student-message-cr-nc-gradeoption-withdrawal-poli.pdf

- Many faculty members have developed an interest in 'specifications grading,' an idea explained in detail in Linda Nilson's Specifications Grading: Restoring Rigor, Motivating Students, and Saving Faculty Time (Stylus, 2014). Importantly, Nilson, a stickler for evidence-based practices, indicates that research on grading suggests that 'pass/fail courses reduce student motivation to learn and excel, while pass/fail grading of assignments and tests increases it, assuming students understand the specs they need to meet for the assignment or test to merit a pass' (POD Discussion Group post, 21 Mar. 2020).

\section{Honors in the Time After Corona}

In Márquez's novel, Florentino and Fermina-the dispirited, star-crossed lovers who have chosen 'social distancing' over scandal and humiliation-end up sailing up and down the Magdalena River 'forever,' self-exiled or 'quarantined' by invention to journey under the 
yellow flag of the cholera pandemic. My use of the novel in relation to our predicaments with Corona is, admittedly, quirky and forced, but let's hope that our fates today are more promising.

COVID-19 has prompted pervasive changes to honors and all of higher education. For many faculty and students around the world, the imposed shifts have diminished the intimate bond between teaching and learning. For others, the 'new normal' has created unexpected opportunities to reflect, experiment, take risks, reprioritize, find different avenues for communication, build intentional communities, accept provocative challenges, and redesign pedagogies-qualities, after all, that we celebrate in honors and in all good teaching and learning.

In a recent communication to members of the European Association for International Education (EAIE, https://www.eaie.org/blog/community-message-sabine-pendl.html), President Sabine Pendl reflects:

'This experience will . . . leave a lasting imprint on every aspect of our lives. We can use this as an opportunity to reflect on our practices and marvel at how radically they had to adapt to this new normal. We can look at this positively and ask ourselves, what have we learned in the process? Maintaining a more digital office space could be one of the developments. Online meetings could become even more mainstream in our sector, reducing greenhouse gases from international travel and positively impacting our work-life balance. I hope that we can continue to adapt to new ways of working, be more open to brave ideas and be more resilient when facing challenges.'

Likewise, in her opinion piece in The Chronicle of Higher Education (24 Mar. 2020), Flower Darby ponders how to 'recover the joy of teaching' in the wake of the disruptions that burden our work and relationships today (see https://www.chronicle.com/article/How-toRecover-the-Joy-of/248314). Will that day pass? Can we restore the love we share for our students, colleagues, programs, colleges?

In another Chronicle article, the author asks, 'How Will the Pandemic Change Higher Education?' (10 Apr. 2020). A group of professors, administrators, staff, and others respond with a variety of prophecies that, despite the array of predictions from the apocalyptic to the bureaucratic to the sardonically amusing, have one vision in common: COVID-19 has inalterably changed why, what, when, and how faculty teach and students learn (see https://www.chronicle.com/article/How-Will-the-Pandemic-Change/248474). The concerned, sincere replies suggest another theme-that teaching and learning, regardless of the mode or setting of engagement, matters. Pandemics, natural disasters, and other dire emergencies will inevitably upset our work, our calling, but they will not erase its value. The joy of what happens in honors along with all our educational efforts that Darby references will prevail in the time of Corona and after.

If the expert epidemiologists are correct, the effects of COVID-19 on our personal and professional lives will linger long after the virus is mitigated by new social behaviors or vaccines, so we need resources that have immediate application but that also can be revisited as we continue to confront new challenges that emerge in future semesters and beyond. My hope in gathering the information, tips, and models that I share in this piece is that honors faculty and students around the world will benefit from useful material that will 
help all of us thrive in our teaching, learning, and programming while we try to stay healthy and safe in the time of Corona.

\section{Acknowledgments}

An earlier version of this note was posted as an unpublished white paper to the NCHC web site and used for an online forum discussion with NCHC members. 